UCRL-ID-116050

\title{
Measurements of Copper-printed Mylar Bonded to G10 Panels
}

\author{
Reserisio \\ APR 05 管的 \\ OSTI
}

C. R. Wuest

C. Milner

G. Mitselmakher

November 11, 1993

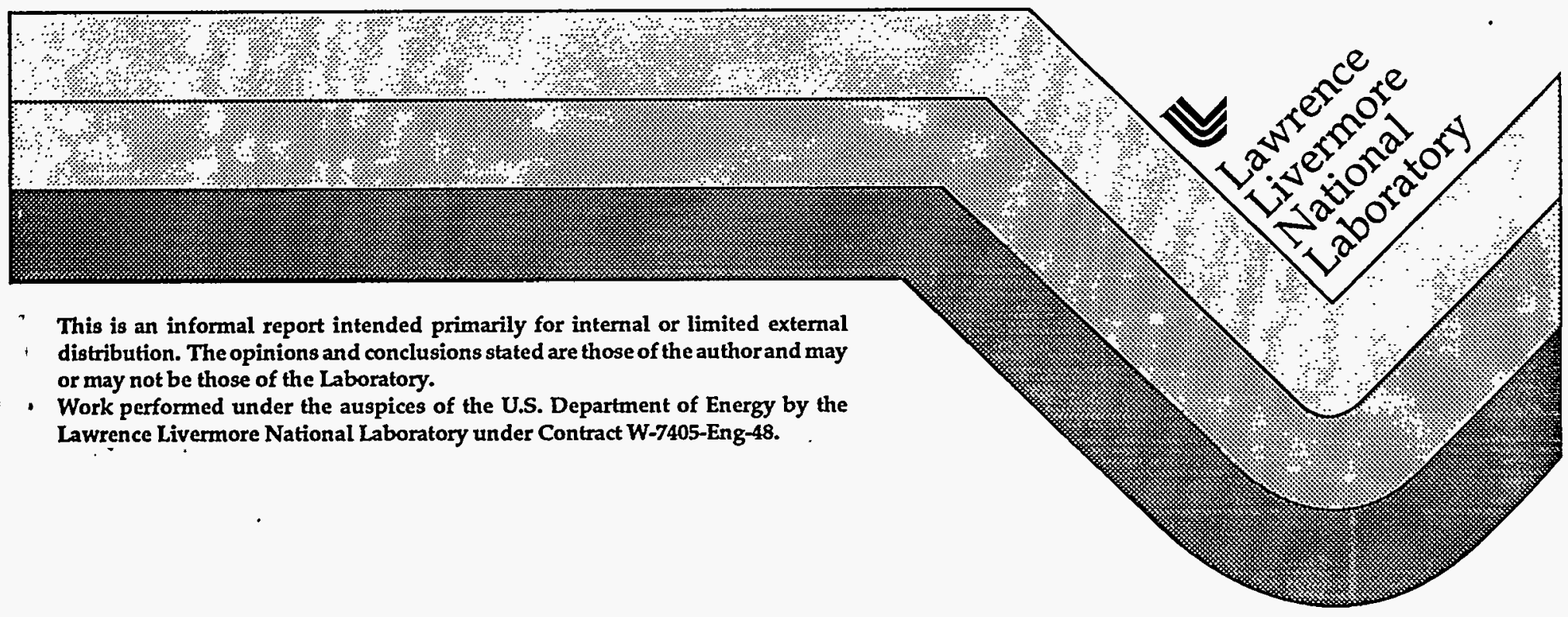

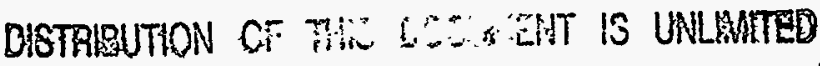




\section{DISCLAIMER}

This document was prepared as an account of work sponsored by an agency of the United States Government. Neither the United States Government nor the University of Californiz nor any of their employees, makes any parranty, express or implied, or 2ssumes any legal liability or responsibility for the accuracy, completeness, or usefulness of any information, apparatus, product, or process disclosed, or represents that its use would not infringe privately owned rights. Reference herein to any specific commercial products, process, or service by trade name, trademark, manufacturer, or otherwise, does not necessarily constitute or imply its endorsement, recommendation, or favoring by the United States Government or the University of California. The views 2nd opinions of authors expressed herein do not necessarily state or reflect those of the United States Government or the University of California, and shall not be used for advertising or product endorsement purposes.

This report has been reproduced

directly from the best available copj.

Available to DOE and DOE contractors from the Office of Scientific and Technical Information

P.O. Box 62, Oak Ridge, TN 37831

Prices available from (615) 576-8401, FTS 626-8401

Available to the public from the

National Technical Information Service

US. Department of Commerce

5285 Port Royal Rd.

Springfield, VA 22161 
GEM TN-93-511

\title{
Measurements of Copper-printed Mylar Bonded to G10 Panels
}

\author{
Craig R. Wuest \\ Lawrence Livermore National Laboratory \\ Cas Milner, Gena Mitselmakher \\ Superconducting Super Collider Laboratory
}

November 11, 1993

\section{Introduction}

We have made measurements of the position of copper strip patterns on 100 micron thick mylar sheets bonded to G10. The purpose of the measurements is to study the concept of printing precision cathode strip patterns on thin mylar and then bonding the mylar to G10 sheets. The motivation of this study is to explore cheaper and simpler methods of fabricating precision cathodes for cathode strip chambers (CSCs) proposed to be used in the GEM Detector muon system ${ }^{1}$ and other high energy physics detector systems at RHIC and CERN. A process of applying strip patterns on mylar has been developed that starts with mylar completely coated with a thin (a few thousand angstroms) layer of copper. A precision printing drum with the proper cathode strip pattern is used to apply an ink to the copper. The printed mylar is then etched in a mild acid solution, removing areas of the copper that are not covered with the ink. After etching the ink is removed leaving a pattern of cathode strips. This method is potentially much cheaper and simpler than the currently envisioned method of producing precision cathode strips on copper-clad G10 using standard printed circuit board layout, photomasks and etchant baths. The major issue to be studied is whether the strips on the thin mylar sheet are printed with the precision necessary for optimal CSC resolution and whether these strips can maintain their precise positions after handling and gluing to G10 substrates. We report here on measurements of $117.5 \mathrm{~m} \mathrm{x} 50$ $\mathrm{cm}$ printed mylar unbonded to $\mathrm{G} 10$, and tests of bonding small $30 \mathrm{~cm} \times 30 \mathrm{~cm}$ printed mylar sheets to $0.5 \mathrm{~mm}$ thick G10 substrates.

\section{Measurements of printed mylar strip precision}

Our first measurements were performed on a $117.5 \mathrm{~cm} \times 50 \mathrm{~cm}$ mylar sheet printed with a simple pattern of $4 \mathrm{~mm}$ wide strips separated by $1 \mathrm{~mm}$. The strips run in the long direction of the sheet. This sheet was taken from a larger roll of printed mylar made available to us by Dr. H. van de Graaf of NIKKHEF in the Netherlands. A specially fabricated vacuum table was made to allow the mylar sheet to be held immobile and flat during measurements. The vacuum table was mounted to a coordinate measuring.machine.and an optical (video) head with a position resolution of $2 \mu \mathrm{m}$ RMS was used under manual operator control to sight on the edges of the strips. Strip straightness and spacing measurements were made for a number of strip locations. We show here representative data from one set of measurements on strip width and strip straightness. 


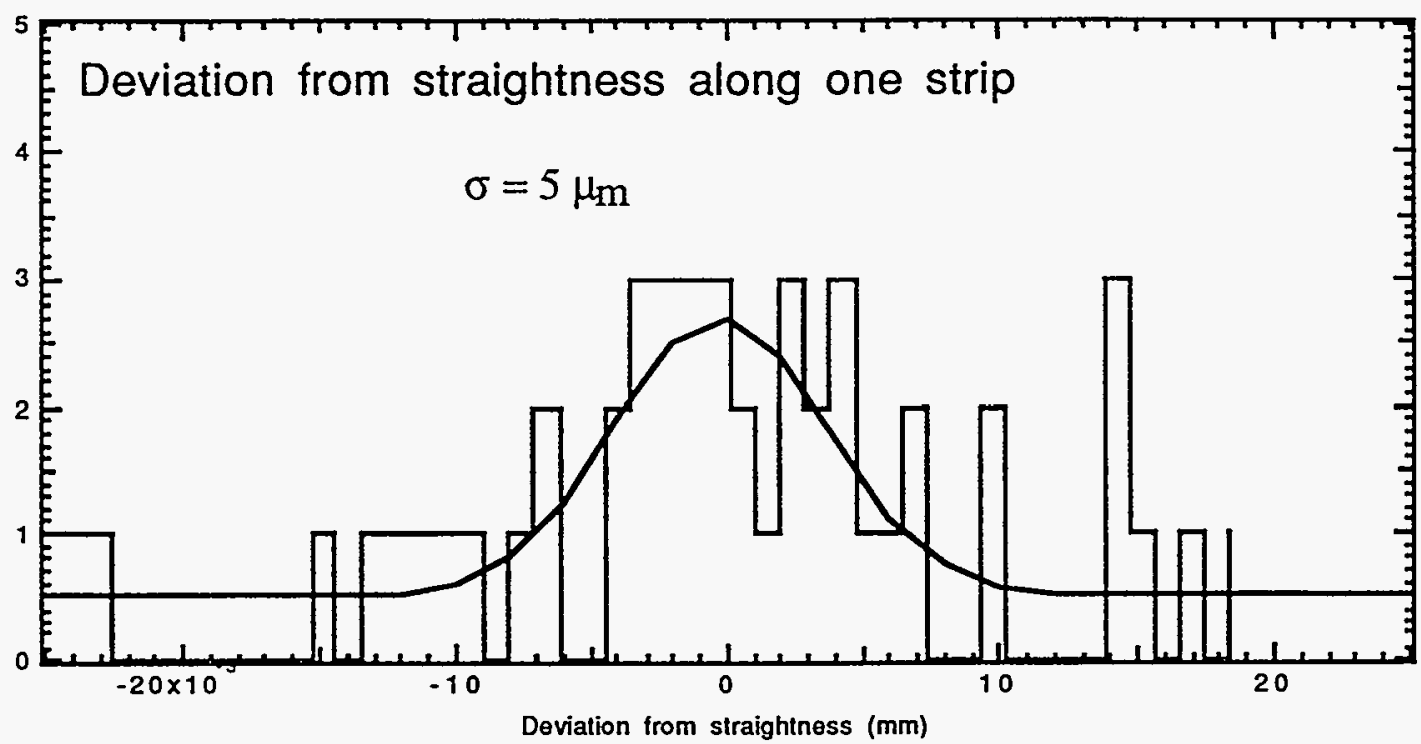

Fig. 1 Deviation from a straight line as measured along one edge of a single strip. 47 measurements were made at $2.5 \mathrm{~cm}$ intervals from 0 to $117.5 \mathrm{~cm}$. The residual is consistent with the measurement error of the CMM optical head.

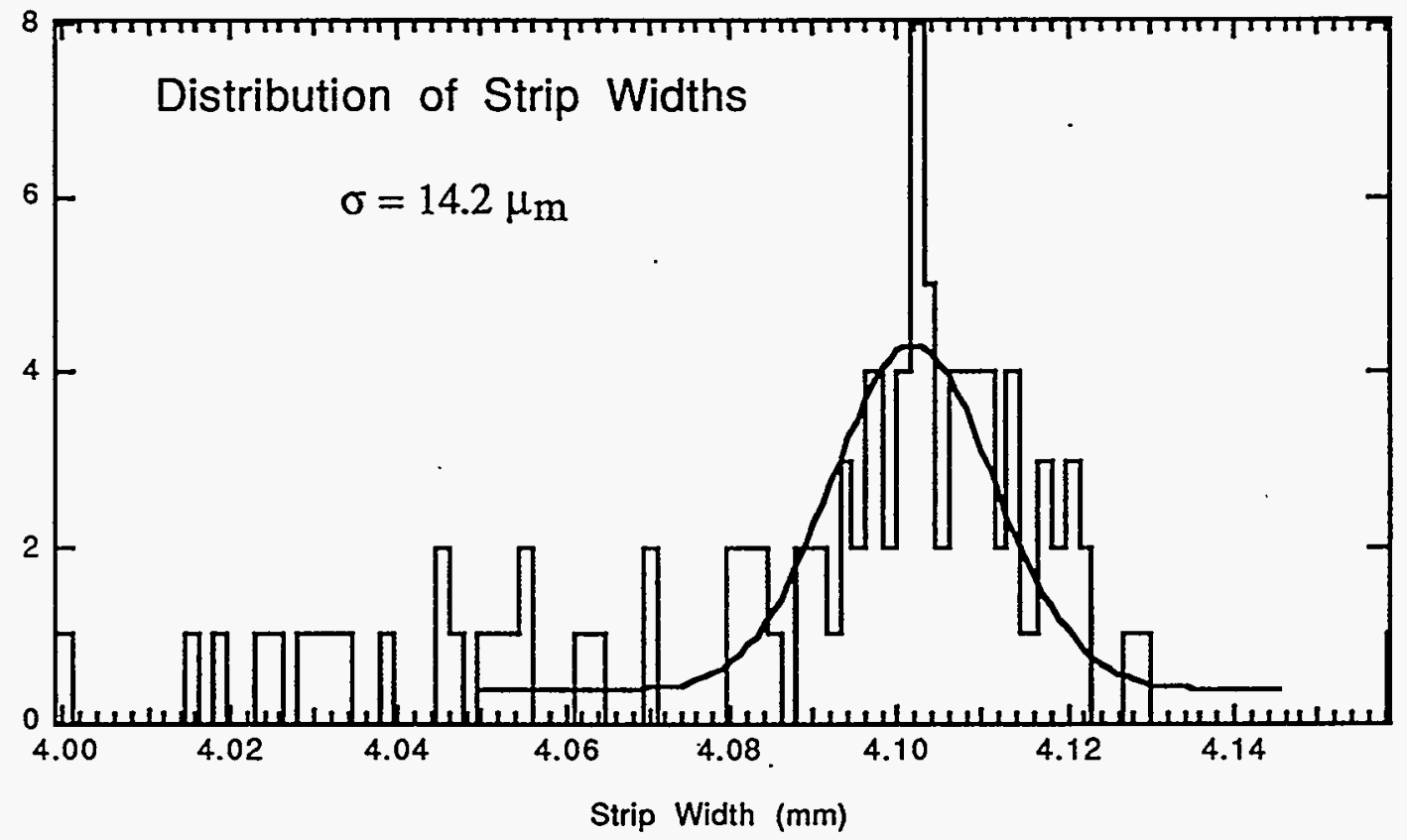

Fig. 2 Distribution of strip widths across the $60 \mathrm{~cm}$ width of the mylar sheet. 95 strips were measured. 


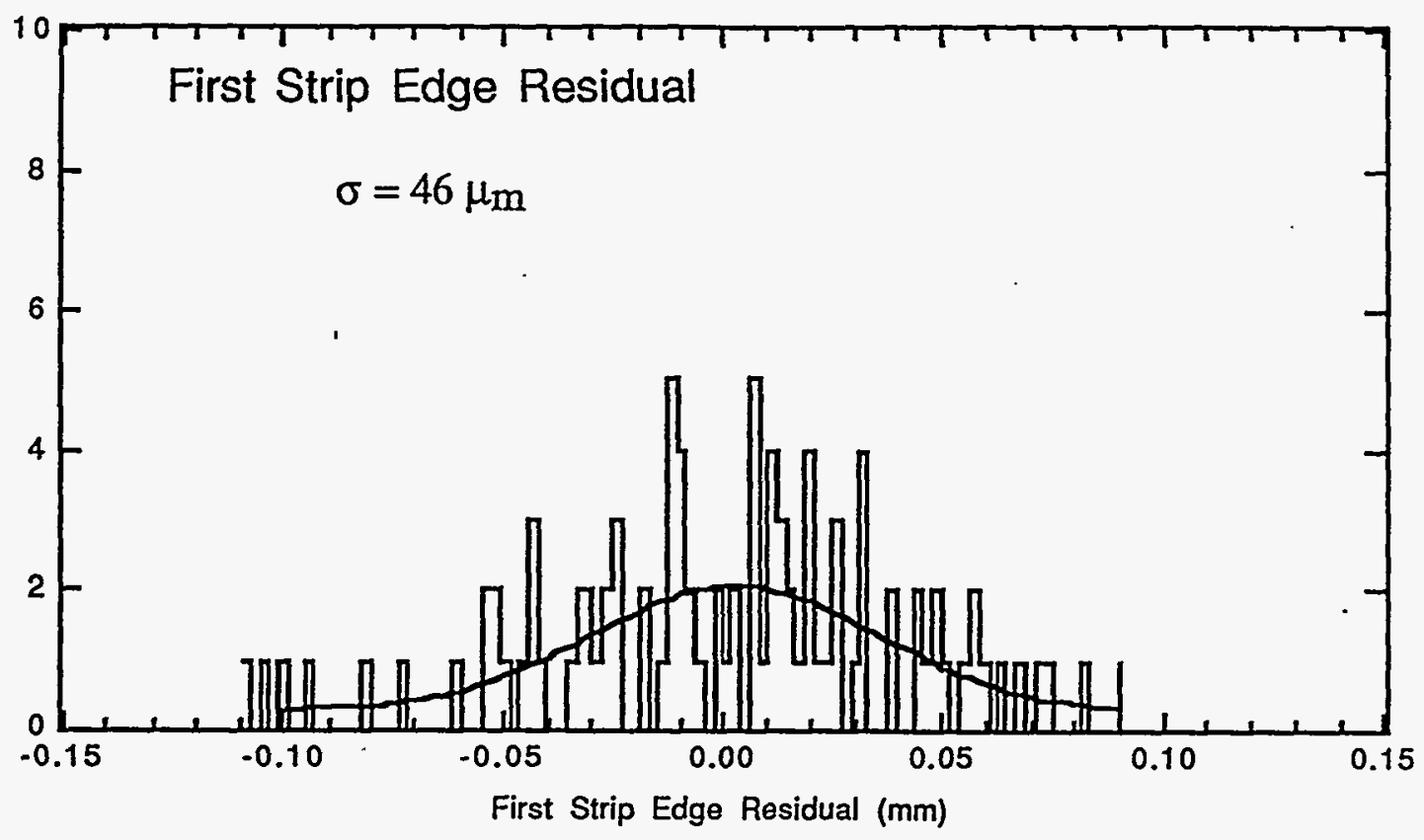

Fig. 3 Distribution of first strip edge deviation from an ideal uniform spacing.

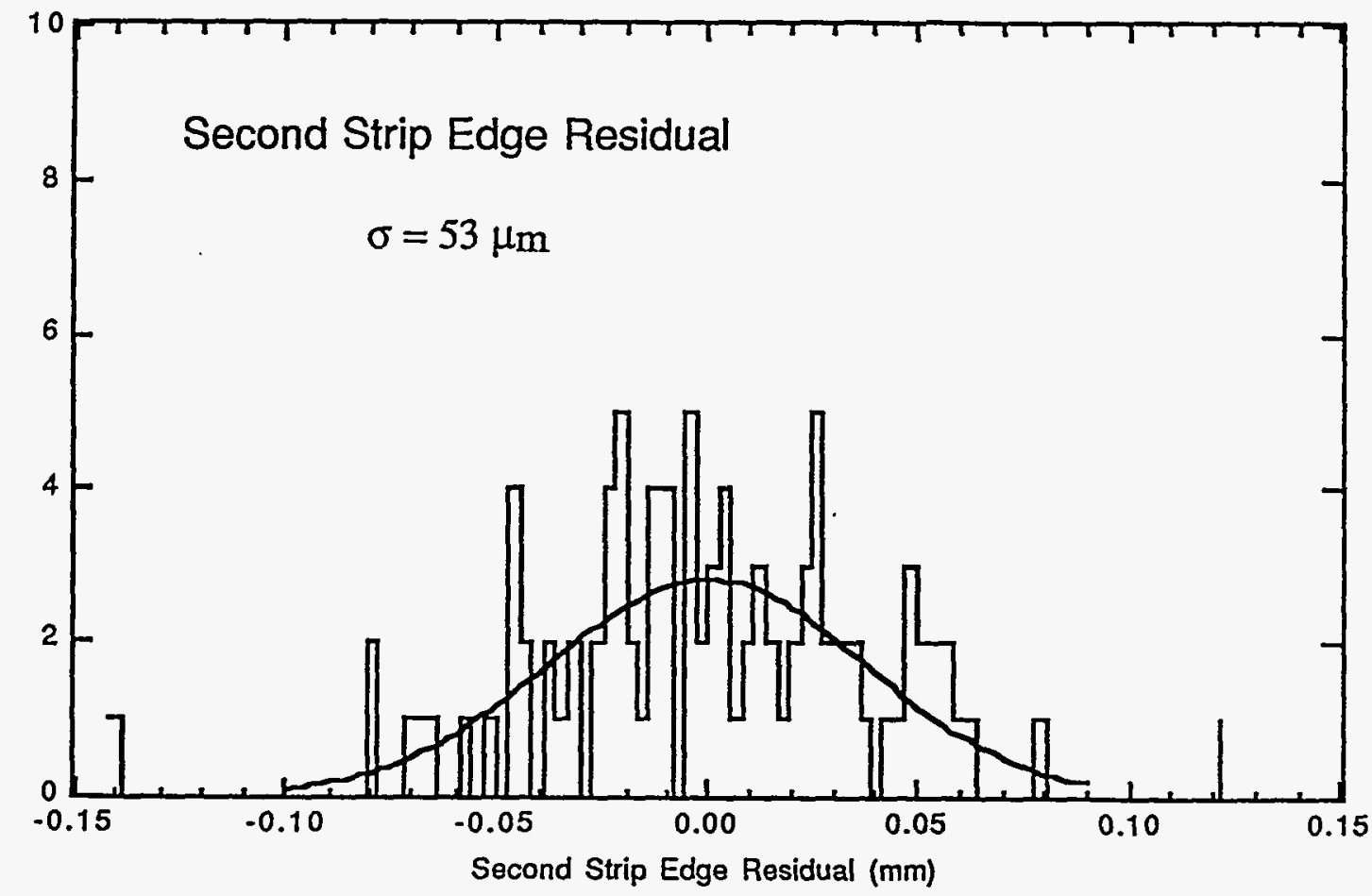

Fig. 4 Distribution of second strip edge deviation from an ideal uniform spacing.

As can be seen in Figs. 1 - 4, the strip positions on the mylar are distributed with a deviation of about $50 \mu \mathrm{m}$. Strip straightness is very good and strip widths are distributed with a sigma of about $14 \mu \mathrm{m}$. Similar results were measured for the strips near the opposite long 
side of the mylar sheet. These results are quite encouraging and meet the specifications for GEM CSCs.

\section{Measurements of printed mylar glued to G10}

The next set of measurements were made on a small $30 \mathrm{~cm} \times 30 \mathrm{~cm}$ sample of printed mylar from the same roll as above. Measurements were made on the mylar prior to gluing to $\mathrm{G} 10$ and after gluing.

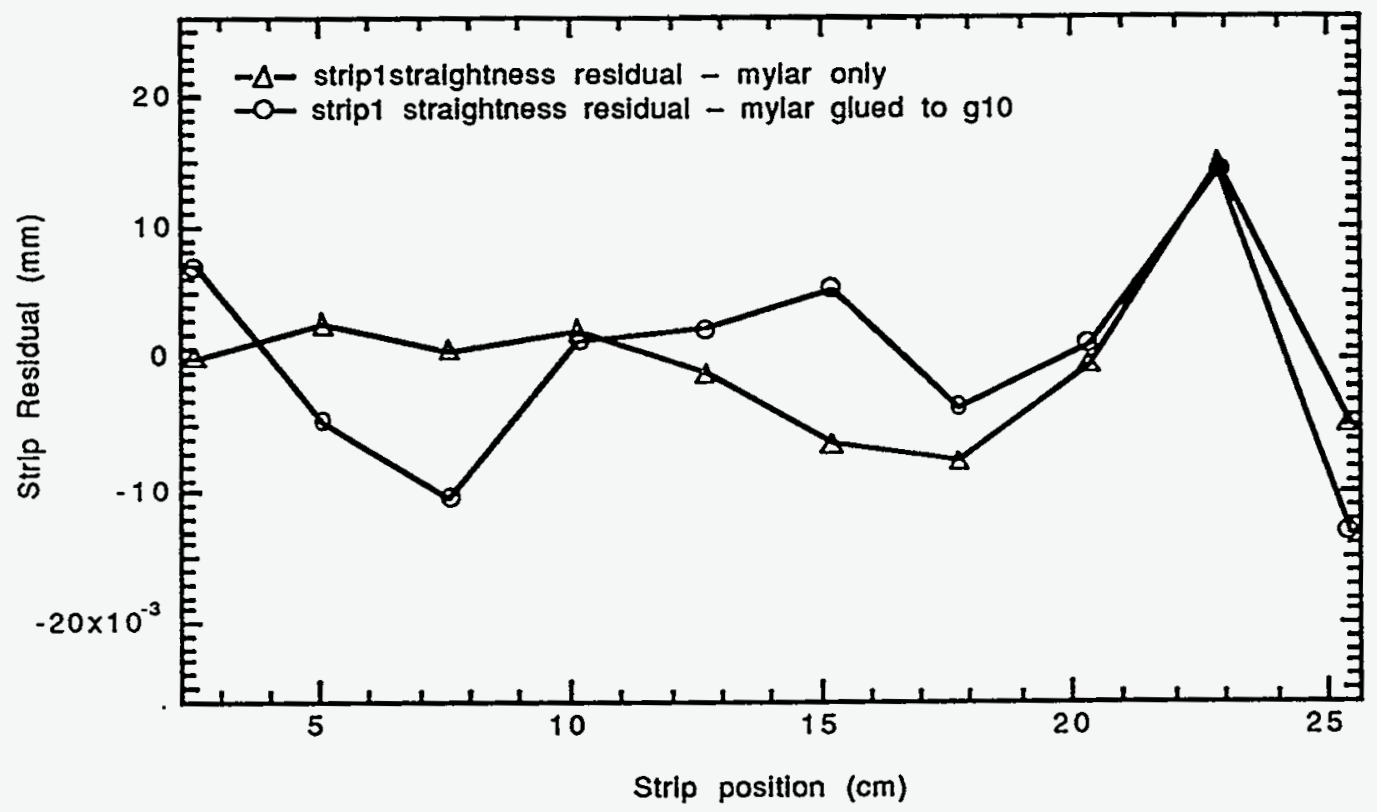

Fig. 5. Deviation from straightness for the same strip before and after gluing to G10.

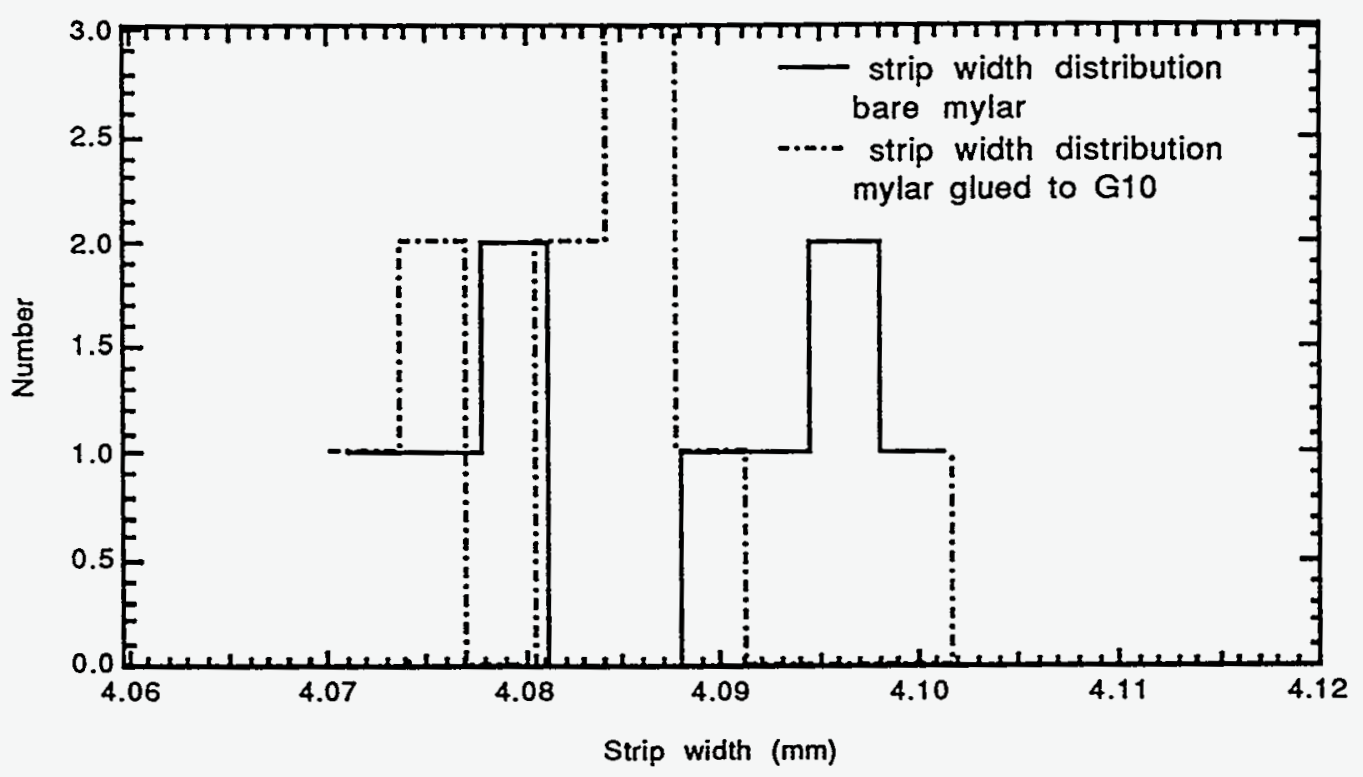

Fig. 6 Width distribution of strips before and after gluing to G10. 
The results shown in Figs. 5 and 6 indicate that there is little, if any, effect on the strip straightness or width after gluing. We will repeat this measurement on a $1 \mathrm{~m}$ long panel in the near future and the results will be reported in a follow-on GEM note.

\section{Acknowledgments:}

We would like to acknowledge the work of Harlan Olson for gluing the mylar to the G10, and Steven Pratuch and Andy Nikitin for performing the measurements on the coordinate measurement machine.

\section{References:}

1. GEM TN-93-262, GEM Technical Design Report, April 30, 1993. 


Technical Information Department - Lawrence Livermore National Laboratory University of California • Livermore, California 94551

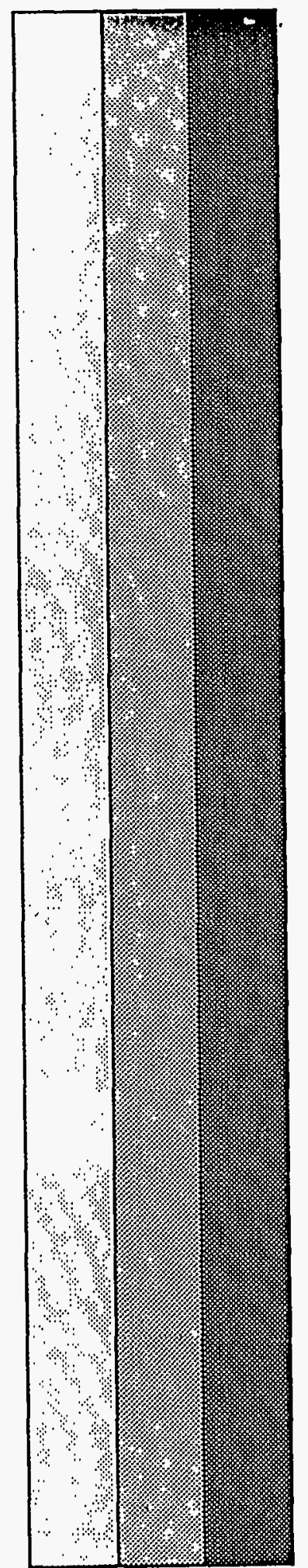

